\title{
A Teaching Model of Urban and Rural Planning Curriculum Integrating Virtual Simulation Technology
}

\author{
https://doi.org/10.3991/ijet.v13i06.8584 \\ Xuhui Wang \\ Northwest University, Xi'an, China \\ Zhao Hao \\ Xi'an City Planning Design and Research Institute, Xi'an, China \\ Sixi Luo( $\left.{ }^{\varpi}\right)$, Meimei Ren \\ Chang'an University, Xi'an China \\ 839377053 eqq.com
}

\begin{abstract}
In the teaching process of Urban and Rural Planning, students not just need to learn relevant theoretical knowledge, but also should flexibly apply relevant theoretical knowledge to practice urban and rural planning. Virtual simulation technology can construct the teaching situation which organically combines theory and practice for the course of Urban and Rural Planning, help students deepen the understanding of theoretical knowledge and enhance theoretical knowledge application and practice ability so as to make up for the defects in Urban and Rural Planning teaching. Thus, virtual simulation technology was integrated in Urban and Rural Planning teaching to form the complete teaching mode in this paper. Practical teaching application shows the teaching mode has good effect on improving students' theoretical knowledge study and practical ability.
\end{abstract}

Keywords_-Virtual simulation; Urban and rural planning; Teaching mode

\section{Introduction}

Virtual simulation technology, also called virtual reality technology, simulates the real system in practical world through information technology system. This technology is a new technology which gradually becomes mature with the continuous development of information technology. In virtual simulation technology, the computer generates a virtual world through technological means. The virtual world may be the projection and reappearance of a real world, or a world which does not exist [1]. In the virtual world, users may interact with the virtual world through auditory sense, tactile sense and visual sense. Like the real world, virtual simulation technology can make the interaction result present in the virtual world [1]. With the development of multiple cuttind0edge techniques such as computer graphics, computer vision and computer simulation technology, authenticity, instantaneity and interactivity of virtual 
simulation technology have developed to a high level, so that it has been widely and deeply applied in many fields [2].

Urban and Rural Planning is a subject with strong practicalness. In the teaching process, students not just need to learn relevant theoretical knowledge, but also should flexibly apply relevant theoretical knowledge to practice urban and rural planning. In traditional course mode of Urban and Rural Planning, the practical link of Urban and Rural Planning is often completed through applying real building and road models or requiring students to draw. Such method is difficult to let students immerse in practical situation of urban and rural planning. Meanwhile, such practice form is usually separated from course teaching [3]. Finally, students cannot closely combine theoretical knowledge and practice of Urban and Rural Planning, which reduces teaching effect. Virtual simulation technology can construct the teaching situation which organically combines theory and practice for the course of Urban and Rural Planning, help students deepen the understanding of theoretical knowledge and enhance theoretical knowledge application and practice ability so as to make up for the defects in Urban and Rural Planning teaching. Therefore, the application of virtual simulation technology in Urban and Rural Planning teaching has great value. The course mode will be deeply studied in this paper.

\section{Review of research status}

As urbanization goes deep in China, higher theory and practice ability has been proposed for the students of urban and rural planning major. How to make students integrate theoretical knowledge and design philosophy of urban and rural planning in practice has been the research emphasis of teaching personnel. Fen et al. [4] comprehensively analyzed the teaching conditions of Urban and Rural Planning in the research process, and conducted the teaching research with the principal line of motivating students' learning interest and cultivating their thinking reason. Song et al. [5] applied SWOT analysis method in strategic management theory to deeply investigate strengths, weaknesses, internal and external environments of Urban and Rural Planning, and proposed the teaching framework of linking SRTP with Urban and Rural Planning.

The third technological revolution dominated by information technology overturned traditional thinking in many fields. Virtual simulation technology which develops in this process can help people experience the real world in the virtual world through constructing a virtual world. Authenticity, instantaneity and interactivity of virtual simulation technology makes it widely applied in the education field, and the good effect has been gained. For example, Liu discussed the application of virtual reality technology in architecture teaching. Through virtual simulation technology, learners can observe the things in the space from various angles so that they can have the brand-new learning feelings so as to promote learning effect [5]. Arain et al. [6] introduced the potential application of Second Life (SL) in strengthening study and training of construction project management. Through the virtual environment, students can visualize the construction projects in $3 \mathrm{D}$. The experiment has verified that 
virtual reality technology contributes to promoting students' learning initiative. Francis et al. [7] deeply discussed the advantage and method of introducing virtual simulation technology in higher education. The author considered the construction of virtual environment could gain the good teaching effect in multiple fields such as business studies, architecture, engineering science and medical science. In the research process, the author proposed the technology and framework for applying virtual simulation technology to conduct immersion teaching in the field of engineering science.

However, in the existing research process, there are short of research achievements on organic combination of virtual simulation technology and Urban and Rural Planning. But, Urban and Rural Planning is a subject with strong practicalness, and it is difficult for the existing teaching mode to construct effective practical situations. Thus, the teaching mode in which virtual simulation technology is integrated is studied in this paper, in the hope of improving teaching effect of Urban and Rural Planning. The innovation of this research is mainly reflected in the following two aspects:

First of all, the teaching mode which integrates virtual simulation technology in Urban and Rural Planning is proposed in this paper. Meanwhile, the principle and general framework of this teaching mode ware constructed so as to offer theoretical basis for teaching Urban and Rural Planning in which virtual simulation technology is integrated. Secondly, based on the teaching mode of Urban and Rural Planning in which virtual simulation technology is integrated, corresponding teaching process is put forward in this paper. The teaching examples are explained from two aspects: teaching stage and tasks in each stage, and the teaching effect was tested.

\section{Teaching mode of Urban and Rural Planning in which virtual simulation technology is integrated}

The teaching mode of Urban and Rural Planning in which virtual simulation technology is integrated combines the advantages and features of virtual simulation technology as well as specific requirements of Urban and Rural Planning. Besides, modularized and staged teaching mode is applied. First of all, the foundation framework for Urban and Rural Planning teaching is constructed by virtual simulation technology. On this basis, the specific teaching module of Urban and Rural Planning is developed.

\subsection{Teaching mode construction principle}

Virtual simulation teaching mode for Urban and Rural Planning needs to organically combine detailed requirements of Urban and Rural Planning teaching with advantages and features of virtual simulation technology, and considers the needs of students with different knowledge and ability. The main purpose of the teaching mode is to construct rich, real-time and interactive practice situations for Urban and Rural Planning through virtual simulation technology. In the teaching mode framework, the following principles should be followed (see fig.1): 


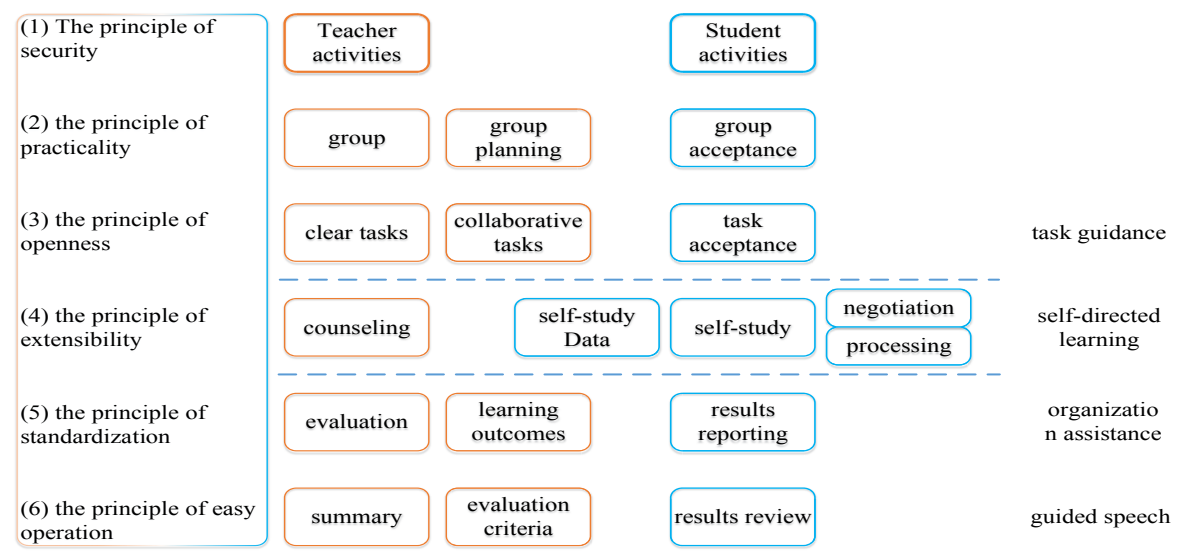

Fig. 1. Teaching thought chart of Urban and Rural Planning in which virtual simulation technology is integrated

1. Security principle. The teaching mode framework constructs a virtual environment through virtual simulation technology for students to practice urban planning. Students may complete the practical environment in the virtual environment according to course requirements and their own understanding. In students' practice process, students may interact with virtual environment and conduct their own operation [9].

2. Practicability principle. The virtual simulation teaching mode is used for Urban and Rural Planning teaching. This requires customized development of the system in accordance with the actual situations of Urban and Rural Planning teaching so as to make sure the system can plan and arrange teaching process as well as provide assignment correction and score management functions.

3. Openness principle. Openness principle means the virtual simulation teaching mode framework should own certain expandability. Teachers may adjust the system according to specific teaching needs so as to achieve individualized customization. When there is tiny change in teaching needs, the system also supports the teacher to modify the system through parameter setting so as to improve teaching efficiency.

4. Expandability principle. Virtual simulation teaching mode offers real-time and interactive practical environment for Urban and Rural Planning. Through this virtual environment, students may freely conduct urban and rural planning practice. Since current urban and rural planning theory and the specific requirements of government for urban and rural planning are in the continuous development and change [10], the teaching process also needs to be expanded and changed.

5. Standard principle. China sets many national standards and industrial standards for urban and rural planning. Hence, the specific planning process must abide by these standards in order to reach the expected purpose and effect [11]. Therefore, these national standards and industrial standards must be followed in the process of constructing virtual simulation teaching mode. 
6. Operability principle. The main feature of virtual simulation teaching mode of Urban and Rural Planning is that, students may utilize virtual simulation environment to effectively practice basic theory of urban and rural planning so as to enhance their theory level and practical ability. Operability principle can make students avoid use of precious time in system operation study, and focus on improvement of theoretical knowledge application and practical ability. Fig. 1 shows teaching mode principles of Urban and Rural Planning in which virtual simulation technology is integrated.

\subsection{General framework of teaching mode}

The general framework of teaching mode of Urban and Rural Planning in which virtual simulation technology is integrated mainly includes two modules: course teaching module and virtual simulation practice module. The system structure is shown in Fig. 2 .

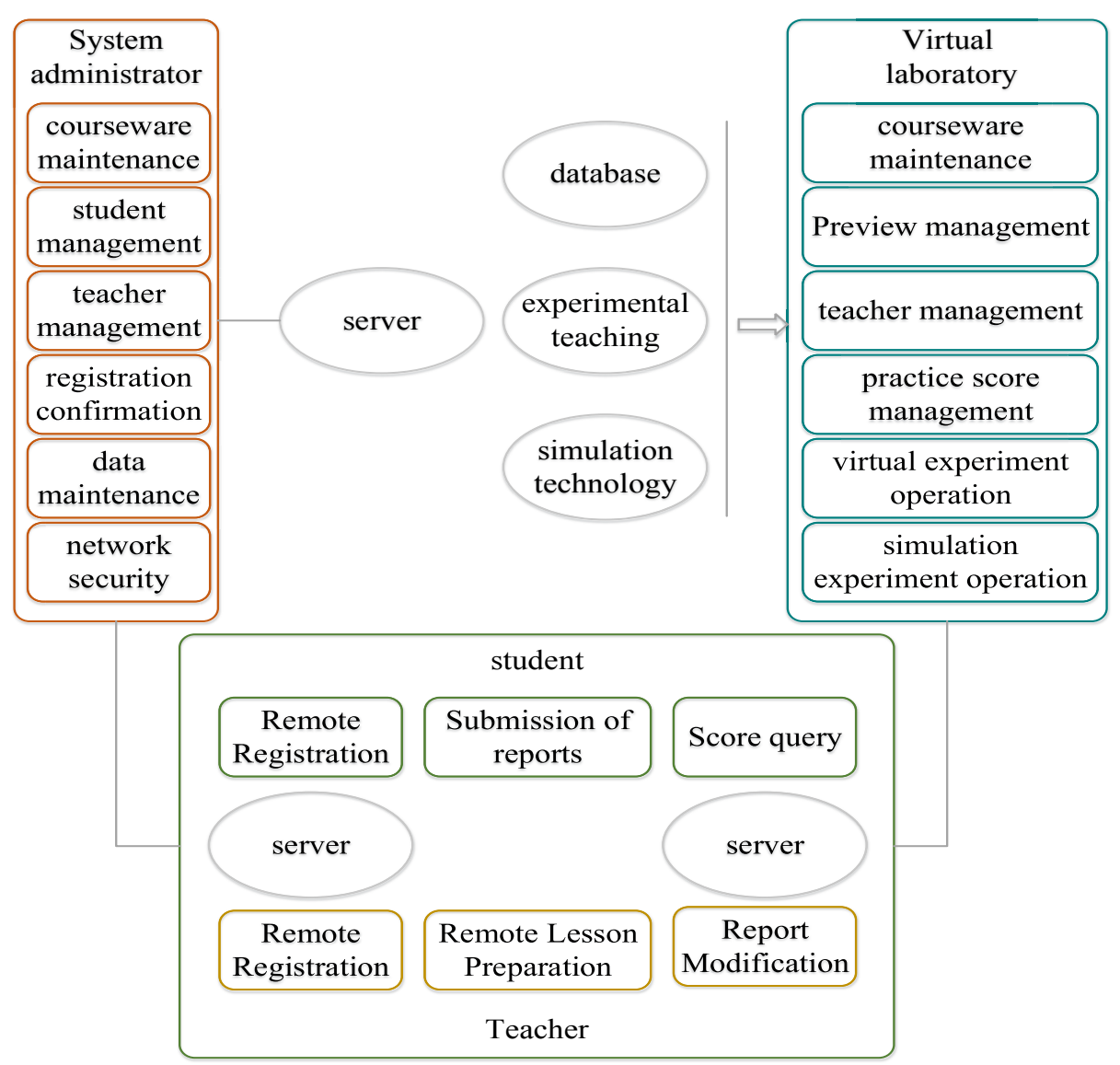

Fig. 2. General framework of virtual simulation teaching mode of Urban and Rural Planning 
The advantage of virtual simulation teaching method of Urban and Rural Planning is as follows: theory teaching and practice teaching serve as a unified whole to formulate practice content in different stages, experimental project, course design and graduation design and form a teaching system which integrates theory and practice. Course teaching module refers to traditional Urban and Rural Planning teaching classroom. The major task of this module is to explain and learn theoretical knowledge of Urban and Rural Planning. This part is the foundation of the whole teaching mode. Only when students own certain theoretical basis can they better apply virtual simulation practice module to verity theoretical knowledge and complete corresponding urban and rural planning practice.

Virtual simulation teaching mode is the core and main innovation point of this teaching mode. The module applies computer graphics, computer vision technology and computer simulation technology to construct a virtual environment. Students may practice urban and rural planning through this virtual environment. Virtual environment also shows the interaction result to students. Students may further modify and optimize the urban and rural planning scheme according to the teaching result shown by the virtual environment. Through virtual simulation teaching module, students may deepen their understanding of theoretical knowledge and enhance their practical ability.

\subsection{Virtual simulation practice module of Urban and Rural Planning}

Virtual simulation practice module integrates course resources and teaching requirements of Urban and Rural Planning and constructs a simulation system for students to complete urban and rural planning practice. The general architecture of this module is shown in Fig.3.

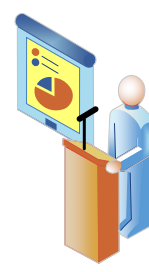

View layer

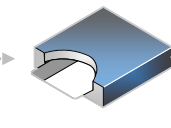

control layer

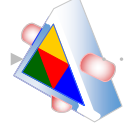

service layer

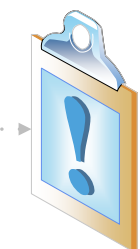

data persistence layer

Fig. 3. General architecture of Virtual simulation practice module of Urban and Rural Planning

Virtual simulation practice module adopts hierarchical architecture, including data persistence layer, service layer, control layer and view layer. Data persistence layer provides persistent resource storage service, including database server and distributed file system server which are respectively used to store relational data as well as the pictures, videos and audio required by virtual simulation system. Service layer implements specific virtual simulation environment and generates the virtual environment through gaining the resources and data gained from data persistence layer. Be- 
sides, it is responsible for receiving processing request from control layer and carrying out corresponding treatment. Control layer is the middle layer of view layer and service layer, responsible for receiving users' request, handling it and sending it to service layer as well as receiving simulation result data from service layer. View layer is responsible for providing users with graphical interfaces to gather users' operation request and sending iy to control layer. Meanwhile, it also receives simulation result data from control layer and presents simulation result through computer graphics.

\section{$4 \quad$ Teaching example and teaching effect}

Urban and Rural Planning is a subject with strong practicalness. Pure theoretical knowledge teaching will let students difficult to fully train and enhance their practical ability. The expected teaching effect may be reached only through organically combining theoretical knowledge and operation time. Based on the teaching mode of Urban and Rural Planning in which virtual simulation technology is integrated, the specific teaching example will be designed in this paper, and the teaching effect will be tested.

\subsection{Teaching example}

The core of enhancing teaching quality of Urban and Rural Planning is to improve course system and teaching content construction so as to promote students' ability to connect theory with practice. To achieve this goal, the core is to increase the proportion of practice module in the course. But, if organic combination of theory teaching and application practice fails, period waste will be caused. The design of teaching example will be conducted from two aspects: teaching order and teaching process.

Selection of teaching order. There are mainly three forms for combining theory with practice: application practice is before theory teaching; application practice is after theory teaching; application practice is embedded in theory teaching. The first form will make students lack guidance of theoretical knowledge in practice and also lack the purpose. As a result, it is hard to achieve the good effect. Although the second form has made students have certain cognition of theoretical knowledge in application practice link, application practice and theory teaching are separated. The third form can keep strong interactivity in teaching process. Students cannot just verify theoretical knowledge in the virtual simulation system in time. Meanwhile, students can grasp students' learning effect in real time so as to optimize the teaching process. Thus, the third form is chosen in this paper to design virtual simulation teaching mode of Urban and Rural Planning.

Teaching process design. The teaching mode of Urban and Rural Planning in which virtual simulation technology is integrated includes four stages: adaptive practice stage, verification practice stage, design practice stage and comprehensive practice stage, as shown in Fig.4. 
Paper-A Teaching Model of Urban and Rural Planning Curriculum Integrating Virtual Simulation ...

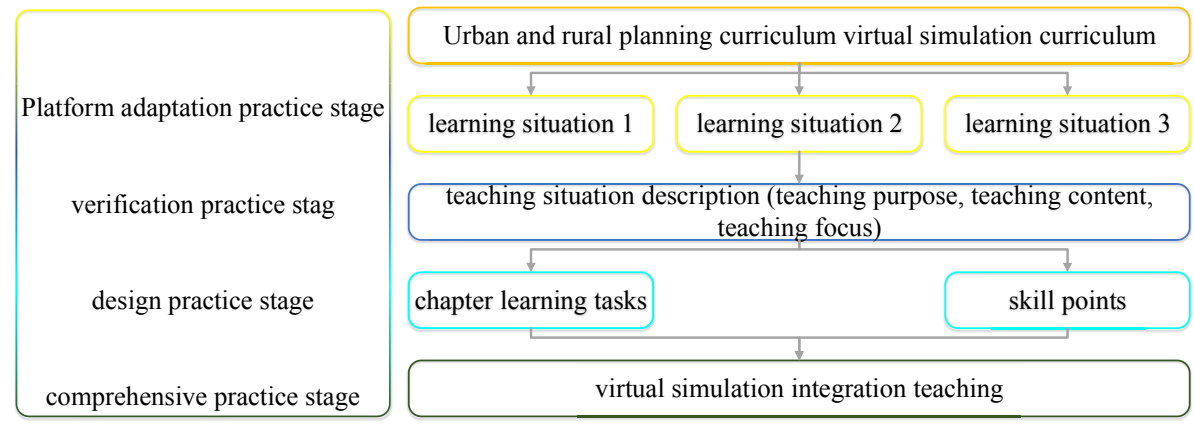

Fig. 4. Teaching process chart of virtual simulation teaching mode

Adaptive practice stage. The main task of this stage is to let students learn theoretical knowledge of Urban and Rural Planning, and make them preliminarily know environment and operation method of virtual simulation system. This stage puts particular emphasis on teacher's explanation in classroom, and considers preliminary statement of virtual simulation system operation. In this stage, students need not grasp the specific urban and rural planning method, but explore basic system operation in a relatively relaxing environment. To cope with possible period shortage, the teacher may distribute system operation manual and let students freely choose time and place to learn basic system operation so as to complete system adaptation training.

Verification practice stage. The main task of this stage is to let students deepen the understanding of basic theory of Urban and Rural Planning through practice, and cultivate students' skills of applying virtual simulation system in design. During designing the practice item, the teacher should reinforce basic principles and design experiment of typical cases so that students can deepen the understanding of course content in practice. For the difference between design mode and design philosophy and occasions applicable, the teacher also should let students observe the differences through corresponding practice link so as to deepen their mastery of key content. In addition, the teacher may acquire students' practice process and problems from the system in real time, and explain them in classroom teaching. Teaching Urban and Rural Planning is taken for example. Fig.5 shows schematic diagram of urban land status. The teacher shows the situation of planning in the virtual simulation system. Students may feel practical application of basic principles of urban and rural road planning from the virtual environment, and analyze the defects so as to deepen their cognition of road planning theory.

Design practice stage. The main task of this stage is to let students comprehensively apply theoretical knowledge of urban and rural planning to finish corresponding planning tasks. In the teaching design of this stage, it is required to fully consider students' practical ability and theoretical knowledge mastery ability, and adopt the layered teaching mode of teaching students according to their aptitudes. In other words, in the design of practice tasks, the tasks may be classified into required task and selective task. The required task puts particular emphasis on the application of basic theoretical knowledge in planning process, and the difficulty is relatively small. 
The selective task stresses planning topics with strong comprehensiveness, and the difficulty is relatively large. All students must complete the planning topics included in the required task. The students with strong learning ability may choose the topics included in the selective task according to their needs. In this stage, students need to apply the knowledge learned to finish a design task within a small area. Fig.6 shows the schematic diagram of a plot in the suburb, and the land nature is for commercial use. The teacher simulated the plot in the virtual simulation system, and asked students to complete planning task for the land. The scope involved in this task is small, so it well adapts to teaching in this stage.

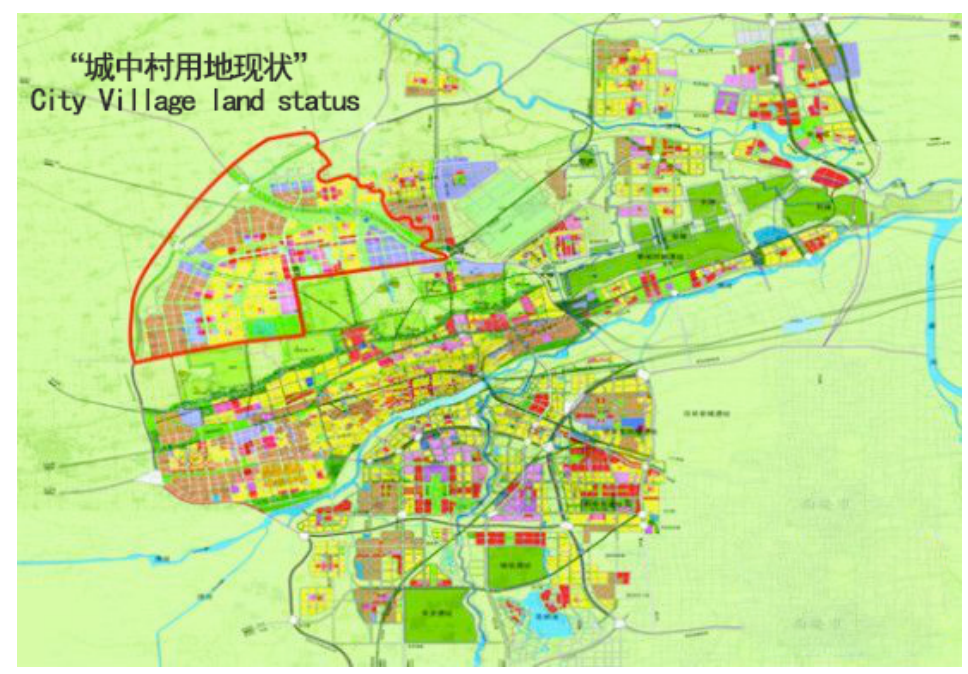

Fig. 5. Schematic diagram of land use of village in the city

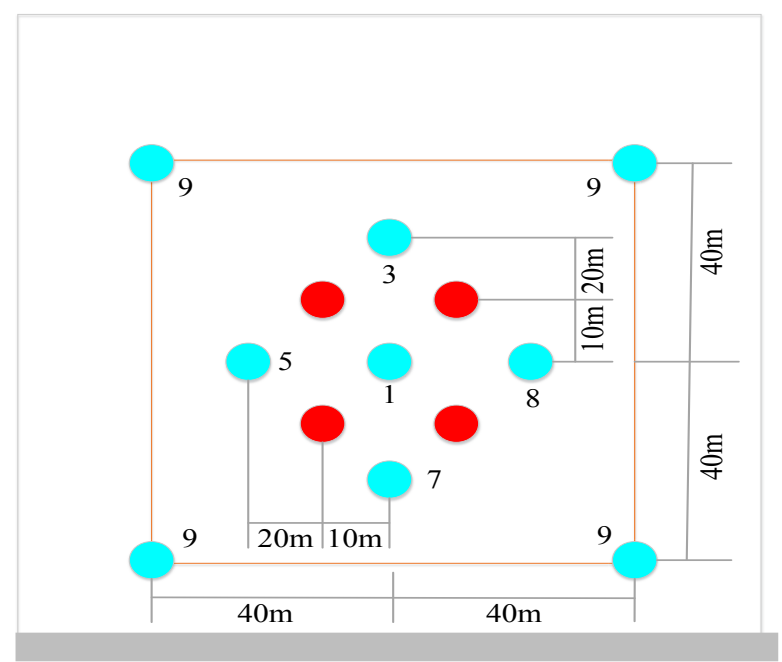

Fig. 6. Schematic diagram of a plot in the suburb 


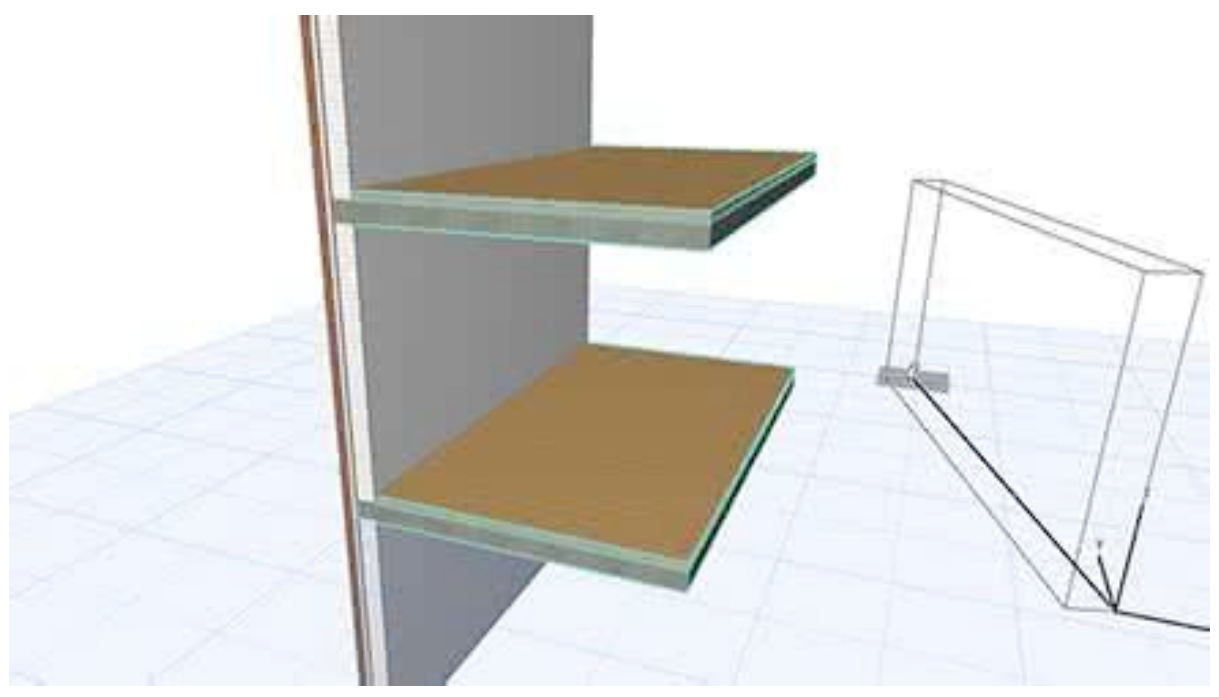

Fig. 7. Architectural design modeling

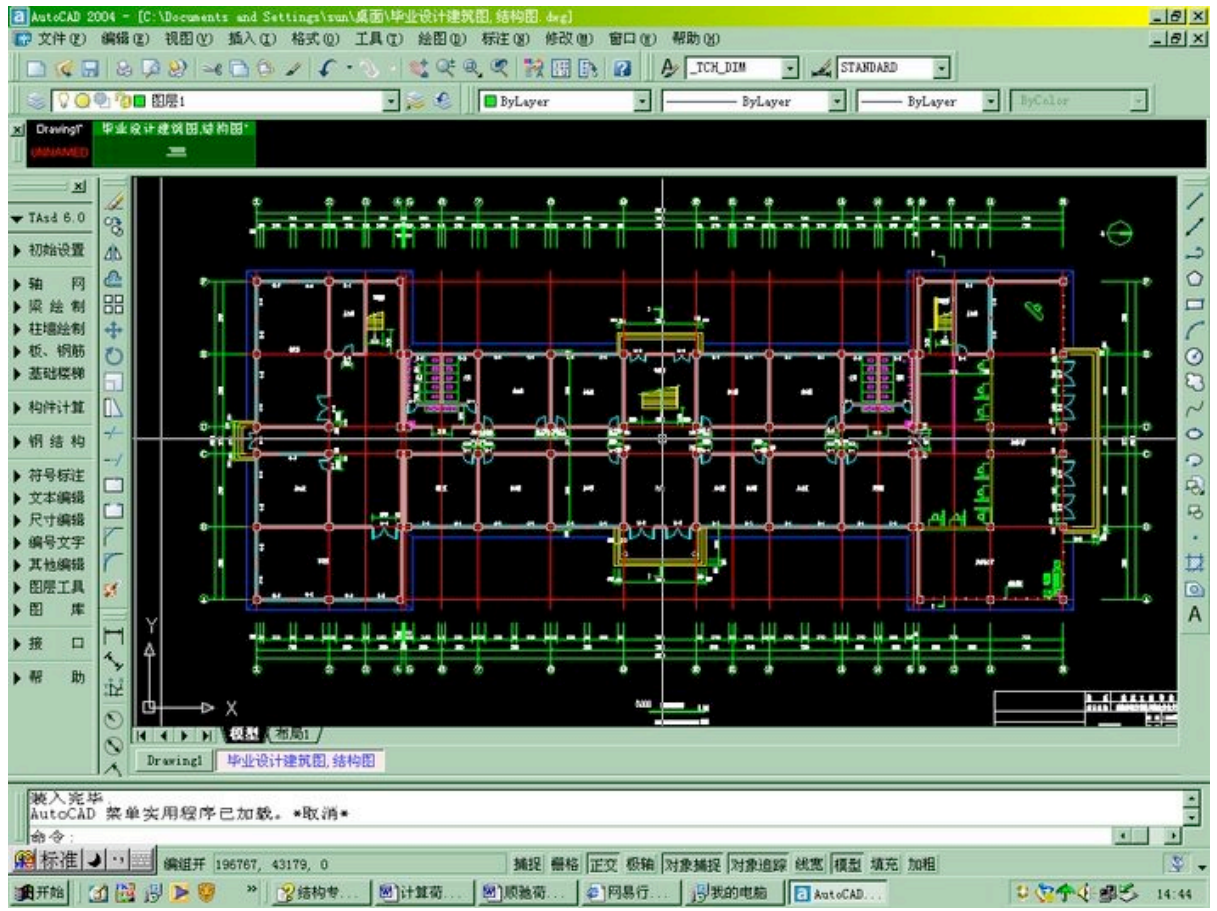

Fig. 8. Software practice stage of architectural design

Comprehensive practice stage. The main task of this stage is to cultivate students' ability to solve practical problems with theoretical knowledge learned in Urban and Rural Planning course. In this stage, the teacher will no longer design the specific 
planning task, but will propose corresponding tasks according to actual urban and rural planning, and require comprehensive application of knowledge for analysis and thinking and give corresponding solutions. In this stage, the mode and process of solving problems will not be specified to give full play to students' innovative ability. With the help of virtual simulation system, students may utilize spare time to complete the tasks. For example, Fig.9 shows simulation effect of the plot in virtual simulation system. Architecture, road and function planning is required for the plot. The teacher simulates the plot through virtual simulation system, and requires students to study the topic in groups and generate the detailed design scheme. The teacher may examine students' designs and put forward the defects.

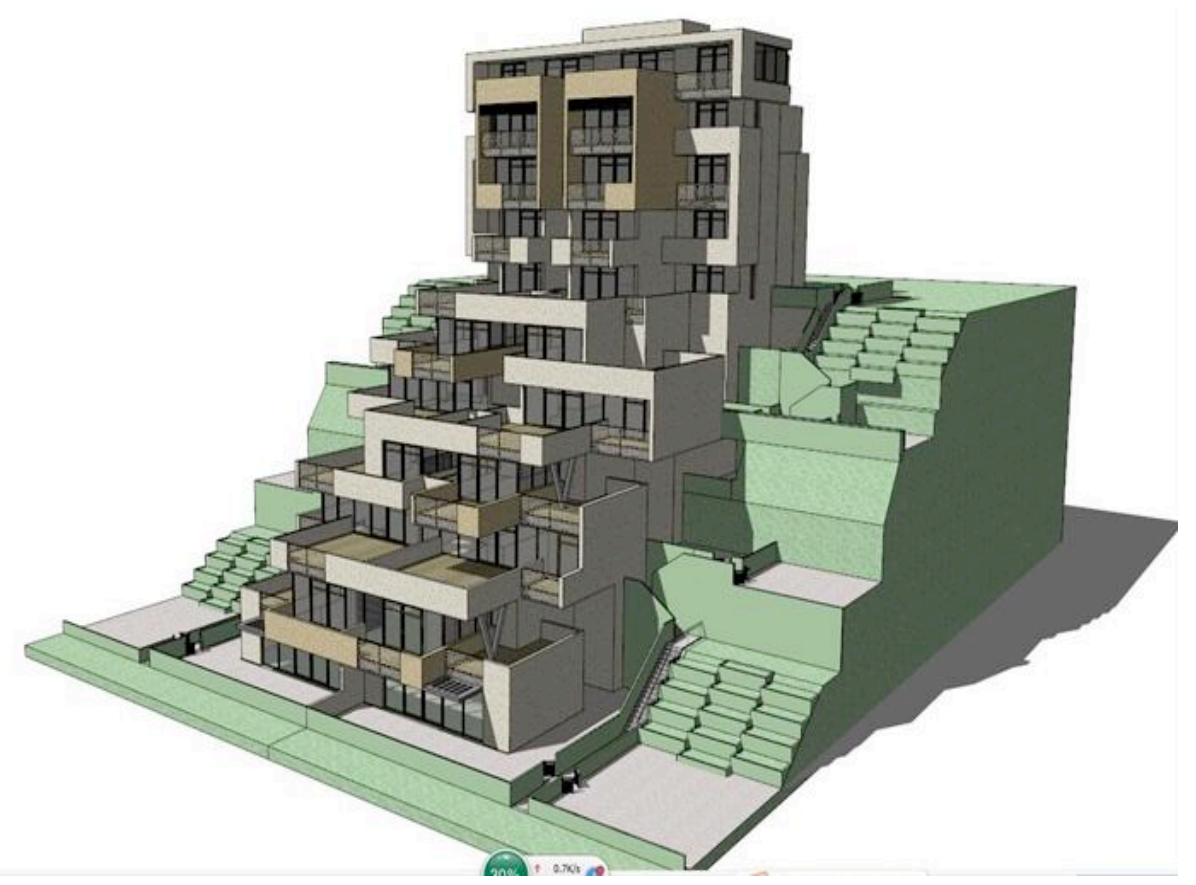

Fig. 9. Simulation effect diagram of virtual simulation system for the plot

\subsection{Teaching effect}

To test the teaching effect of teaching mode in which virtual simulation technology is integrated, this mode was applied in the teaching process. Meanwhile, a class was chosen as the control group. Traditional teaching mode was still applied for the control group. After the course ended, corresponding test paper was designed for experimental group and control group. The main content of the test paper was the course content of Urban and Rural Planning, and the full score was 100. The test results are shown in Tab.4-1. SPSS statistics software was used for data statistics, and test was applied for data test. When, this means the difference between two groups has statistical significance, the calculation of $t$ value is shown in Formula 1. 


$$
t=\frac{\bar{x}-u}{\frac{\sigma_{x}}{n-1}}
$$

According to Table 1, the performance of experimental group is obviously superior to that of control group, indicating the course mode proposed in this paper has gained the expected teaching effect.

Table 1. Result comparison of both groups

\begin{tabular}{|l|c|c|c|c|}
\hline \multicolumn{1}{|c|}{ Group } & Average score & Standard deviation & t & P \\
\hline Control group $(\mathrm{n}=45)$ & 81.20 & 4.67 & \multirow{2}{*}{3.621} & \multirow{2}{*}{0.001} \\
\hline Experimental group $(\mathrm{n}=45)$ & 76.23 & 6.82 & & \\
\hline
\end{tabular}

Except testing the teaching effect through the test paper, the questionnaire was also designed to evaluate the reaching effect of both groups, including learning initiative, practical ability training, theoretical knowledge mastery, innovation ability training and problem solving ability. Students evaluated according to their performance and feeling in the learning process, and each item included two dimensions: "agree" and "disagree". The questionnaire was filled in in the form of anonymity. A total of 90 questionnaires were distributed, and 90 effective questionnaires were recovered, with the recovery rate of $100 \%$. In data statistics, SPSS software was applied, and $x^{2}$ test was used for data test. When $\mathrm{P}<0.05$, this means the difference between two groups has statistical significance. The calculation of $x^{2}$ is shown in Formula 2. We can see from Table 2 that, Urban and Rural Planning teaching mode in which virtual simulation technology is integrated has the significant effect in learning initiative, practical ability training, theoretical knowledge mastery, innovation ability training and problem solving ability.

$$
x^{2}=\sum_{i=1}^{k} \frac{\left(f_{i}-n p_{i}\right)^{2}}{n p_{i}}
$$

Table 2. Statistical result of questionnaire survey

\begin{tabular}{|l|c|c|c|c|}
\hline \multicolumn{1}{|c|}{ Item } & $\begin{array}{c}\text { Control group } \\
(\mathbf{n = 4 5 )}\end{array}$ & $\begin{array}{c}\text { Experimental group } \\
(\mathbf{n = 4 5 )}\end{array}$ & $x^{2}$ & $\mathbf{P}$ \\
\hline Learning initiative & 43 & 29 & 13.617 & 0.000 \\
\hline Practical ability training & 42 & 26 & 9.891 & 0.001 \\
\hline Theoretical knowledge mastery & 44 & 28 & 11.091 & 0.000 \\
\hline Innovation ability training & 41 & 30 & 10.021 & 0.001 \\
\hline Problem solving ability training & 42 & 29 & 8.098 & 0.002 \\
\hline
\end{tabular}


Paper-A Teaching Model of Urban and Rural Planning Curriculum Integrating Virtual Simulation ...

\section{Conclusions}

Urban and Rural Planning as a subject with strong practicalness not just requires students to grasp theoretical knowledge, but also requires them to own corresponding ability to link theory with practice. To improve the teaching effect of Urban and Rural Planning, virtual simulation technology was integrated in Urban and Rural Planning teaching to develop a new teaching mode for the course. Meanwhile, the teaching effect of this mode was tested. The results show that, this teaching mode has good application effect on students' theoretical knowledge mastery and ability training. In conclusion, the integration of virtual simulation technology in Urban and Rural Planning has the following three advantages:

Firstly, the teacher may design corresponding course tasks in the virtual simulation system according to teaching progress and actual needs so as to organically combine theoretical knowledge study and practical ability training. Virtual simulation experiment platform can make students finish experiments without time and space restrictions, which greatly saves the time of both teachers and students.

Secondly, in this teaching mode, the teacher may acquire students' learning conditions and their weak links in real time so as to adjust teaching content and method in time. Virtual simulation experiment can not just relieve period contradiction, well reach the preview purpose and expand the experiment content, but also break the limit of traditional experiment, integrate and optimize experiment resources as well as make the best of superior experiment resources.

Finally, this teaching mode offers the strong support for students to overall apply the knowledge in analyzing, thinking and solving the specific urban and rural planning problems. Distance virtual simulation experiment impossibly rejects or replaces current object experiment form, but can enhance students' enthusiasm and initiative for experiment participation and make students fully exploit their thinking. In one word, it has good effect on students' innovation ability training and problem solving ability training. The course reform for Urban and Rural Planning based on virtual simulation technology is a topic worthy of exploration.

\section{Acknowledgment}

This work was supported in part by the Research project on major theoretical and practical problems in the social sciences of Shaanxi (2017C017), The youth fund project of the humanities and social sciences of the Ministry of Education (16YJCZH140) and Project funding program for basic scientific research services (HUMANITIES AND SOCIAL SCIENCES) projects in central colleges and Universities $(310841170662,310828160425)$. 
Paper-A Teaching Model of Urban and Rural Planning Curriculum Integrating Virtual Simulation ...

\section{$7 \quad$ References}

[1] Jenson, C.E., Forsyth, D.M. Virtual reality simulation: using three-dimensional technology to teach nursing students. Computers Informatics Nursing Cin, 2012, vol. 30(6), pp. 312318. https://doi.org/10.1097/NXN.0b013e31824af6ae

[2] Ricci, S., Peeters, B., Fetter, R., Boland, D., \& Debille, J. Virtual shaker testing: simulation technology improves vibration test performance. Optics Letters, 2008, vol. 30(15), pp. 2010-2012.

[3] Song, S.H. Research on the teaching reform of the drawing course in urban and rural planning majors. Experiment Science \& Technology, 2011, vol. 9(1), pp. 129-131.

[4] Xu, J.F. On teaching difficulties and innovative practice for planning design courses in civilian-run colleges. Shanxi Architecture, 2014, vol. 40(7), pp. 250-252.

[5] Song, S.P., Zhu, F.F. The curriculum framework of computer aided design course for urban and rural planning. Education Teaching Forum, 2017, vol. 8, pp. 257-258.

[6] Arain, F.M., \& Burkle, M. Learning construction project management in the virtual world: leveraging on second life. Electronic Journal of Information Technology in Construction, 2011, vol. 16, pp. 243-258.

[7] Francis, K.B., Terbeck, S., Briazu, R.A., Haines, A., Gummerum, M., \& Ganis, G., et al. Simulating moral actions: an investigation of personal force in virtual moral dilemmas. Scientific Reports, 2017, vol. 7(1), pp. 1-11. https://doi.org/10.1038/s41598-017-13909-9

[8] Pudane, M., Lavendelis, E., \& Radin, M.A. Human emotional behavior simulation in intelligent agents: processes and architecture $i$. Procedia Computer Science, 2017, vol. 104, pp. 517-524. https://doi.org/10.1016/j.procs.2017.01.167

[9] Hu, H.F. Construction of practical course of "meteorological radar principle" based on virtual simulation technology. Education Teaching Forum, 2017, vol. 37, pp. 53-55.

[10] Zheng, L. Influence of unbalanced finance development on the income gap between urban and rural areas under planning urban and rural areas as a whole: taking chongqing as the example. Journal of Chongqing University of Posts \& Telecommunications: social Science Edition, 2012, vol. 24(4), pp. 104-109.

[11] Jiang, L.D., \& Zhang, Z.L. Urban-rural integration planning: theory and practice in suzhou, china. Advanced Materials Research, 2011, vol. 243-249, pp. 6729-6733.

\section{Authors}

Xuhui Wang is a doctor in the College of Urban and Environmental Science, Northwest University, Xi'an 710127, China (wxhxbdx@sina.com).

Zhao Hao is an associate professor in the Xi' an city planning design and research institute, Xi'an 710064, China (Zhangquan@sina.com).

Sixi Luo is a Master in the School of Architecture, Chang'an University, Xi'an 710064, China (839377053@qq.com).

Meimei Ren is a Master in the School of Architecture, Chang'an University, Xi'an 710064, China (839377053@qq.com).

Article submitted 17 March 2018. Final acceptance 23 April 2018. Final version published as submitted by the authors. 